\title{
Awareness of nursing students on legal and ethical issues in day-to-day practice at a teaching hospital in Shillong, northeast India
}

\author{
Ropmay $\mathrm{AD}^{1}$, Nath $\mathrm{A}^{2}$, Patowary $\mathrm{AJ}^{3}$, Slong $\mathrm{D}^{4}$, Bhattacharyya $\mathrm{H}^{5}$, Das $\mathrm{H}^{6}$ \\ ${ }^{1}$ Associate Professor, Department of Forensic Medicine \\ ${ }^{2}$ Senior Resident, Department of Forensic Medicine \\ ${ }^{3}$ Professor and Head, Department of Forensic Medicine \\ ${ }^{4}$ Assistant Professor, Department of Forensic Medicine \\ ${ }^{5}$ Assistant Professor, Department of Community Medicine \\ ${ }^{6}$ Tutor/Clinical Instructor, College of Nursing, \\ North Eastern Indira Gandhi Regional Institute of Health and Medical Sciences, (NEIGRIHMS), \\ Shillong 793018
}

Corresponding Author: Dr. A.D. Ropmay

E-mail: drdonna@rediffmail.com

\begin{abstract}
Background: In the current corona crisis, nurses are likely to face increasing legal and ethical challenges in the path of their industrious career. We have conducted this research to explore the awareness of nursing students on these issues which, we feel, is essential to enable them to deal with practical situations in future

Methods: A total of 162 participants were included in the study. Data was collected with the help of a structured self-administered online questionnaire comprising socio-demographic variables and fifteen items related to the research topic. Analysis was done using SPSS version 11 by descriptive and inferential statistics.

Results: Most of the participants (60.5\%) demonstrated fair awareness according to the criteria in the research tool. Around 55.5\% were aware of the code of ethics for nurses in India and a majority $(92.6 \%)$ knew about the concept of patient autonomy in nursing ethics. However, there was no association between level of awareness with age, gender, and duration of clinical exposure.

Conclusion: These findings emphasize the importance of incorporating ethics and law in the curriculum and reinforcement by problem-based learning to better equip students for real life clinical scenarios in a post-pandemic world.
\end{abstract}

Key Words: nursing students, awareness, ethics, law, curriculum.

\section{Introduction}

The field of nursing is perhaps one of the most demanding professionally and personally as the nurse dedicates her time and talents selflessly for the wellbeing of others. During the historic Crimean War (1853-56), the services of Florence Nightingale as a nurse caring for the sick and wounded round the clock earned her the distinction of being called "Lady with the Lamp"- which has become a symbol of good nursing practice to this day. Through the years, nurses have shown compassion and competence in the face of moral, ethical, and legal dilemmas in the path of their industrious career. These challenges are no less today - if at all, they have escalated by leaps and 
bounds especially after the corona pandemic of 2020 which has changed our lifestyle and work practices completely. Therefore, those on the road to becoming nurses have to be well prepared mentally and physically to weather the storms of their professional lives.

In the present scenario, nurses are likely to face increasing legal and ethical challenges with respect to triage and treatment of patients, particularly those belonging to vulnerable groups such as children, the elderly, pregnant women, and those with co-morbid conditions. Meanwhile, the conventional principles of consent, confidentiality and autonomy continue to apply at all times. In addition, nurses have to assist doctors in handling cases of accident, trauma and assault which have medico-legal implications.

The legal and ethical aspects of day-to-day practice are taught to nursing students throughout the B.Sc (Nursing) course. The content and quality of training that students receive is thus pivotal in preparing them for their role as healthcare providers of tomorrow. We have conducted this research with a view to exploring the awareness of nursing students on the legal and ethical aspects of routine nursing practice - an essential ingredient of a good and positive holistic health outcome. It is imperative for students to be aware of these issues right from the early stages of their training so that they can deal with them confidently at their designated places of work as they attend to the call of duty in any kind of situation.

\section{Methodology}

The present study was performed on four batches of nursing students of the first, second, third and fourth years of the B.Sc. (Nursing) course. As each batch has around 50 students, the target sample size was 200 participants. Data was collected in the form of a structured self-administered online questionnaire comprising socio-demographic variables (age, sex, years of clinical exposure) and 15 (fifteen) items related to the topic of the study over a period of one week, i.e. from 8th to 14th December 2020. This information was entered in MS Office Excel 2007 spreadsheet and analysed using SPSS Version 11 by descriptive and inferential statistics. Responses were evaluated and each correct answer was awarded one mark. There was no negative marking for wrong answers. The total marks secured were computed out of fifteen and percentages calculated for each individual response.

Awareness of nursing students was graded on the basis of scores obtained as follows:-

Good - $\geq 75 \%$

Fair $-50-74 \%$

Poor $-<50 \%$

Statistical Analysis: Pearson's Chi Square and Fisher's Exact Tests were employed to find out if there is significant association between level of awareness with age, gender and duration of clinical exposure in the sample population. A p-value of $<0.05$ was considered as statistically significant. The reliability of the questionnaire was assessed by tabulating the responses of twenty nursing students and calculating Cronbach's Alpha value which was found to be an acceptable 0.74.

The identity of individual responses was kept anonymous and confidentiality of data maintained by the investigators. Adequate information for participants about details of the study was included in the online form prior to filling out the questionnaire and consent taken for the same. Ethical approval for the project was obtained from the Institutional Ethics Committee (IEC) on 18th September, 2020.

\section{Results}

A total of 165 responses were received through the online mode out of which three were incomplete/duplicated and not taken up for analysis. Therefore, the final sample size was 162 (one hundred sixty-two). Results are tabulated in Tables 1-3 and Figure 1.

The majority of respondents were female (93.2\%) and only $6.8 \%$ were male in the age group ranging from 18-26 years with a mean age of 21.29 years. Among the students, $47.5 \%$ had more than 3-4 years of clinical exposure during the course of their practical postings (Table 1). 
Table 1: Socio-demographic characteristics of study participants $(n=162)$

\begin{tabular}{|c|c|c|}
\hline Age & Frequency & Percentage (\%) \\
\hline Age range & & 59.3 \\
18-21 years & 66 & 40.7 \\
$\geq 22$ years & 11 & 6.8 \\
\hline Gender & 151 & 93.2 \\
Male & & \\
Female & 42 & 26 \\
\hline Duration of clinical exposure & 43 & 26.5 \\
<1 year & 77 & 47.5 \\
1-2 years & 162 & 100 \\
\hline 3-4 years & & \\
\hline Course of study & & \\
B.Sc (Nursing) & &
\end{tabular}

In the present study, the mean awareness score was $10.27 \pm 1.03$ with a range of 2-15. Most of the participants (60.5\%) demonstrated fair awareness of the legal and ethical aspects of nursing practice according to the criteria in the research tool (Table 2). Around 55.5\% were aware of the code of ethics for nurses framed by the Indian Nursing Council and published in the year 2006. More than half of the students (54.3\%) knew about recent guidelines from the Ministry of Health and Family Welfare on medico-legal examination of survivors of sexual violence. In relation to consent for minors in the absence of parents, $76.5 \%$ were able to pick the correct option that the hostel warden is authorized to give written consent when a 12-year-old boy residing away from home requires immediate surgery.

Table 2: Awareness of study participants $(n=162)$

\begin{tabular}{|l|c|c|}
\hline \multicolumn{1}{|c|}{ Item } & $\begin{array}{l}\text { No. of correct } \\
\text { responses }\end{array}$ & Percentage (\%) \\
\hline Awareness about INC\# code of ethics for nurses in India & 90 & 55.5 \\
\hline $\begin{array}{l}\text { MoHFW* guidelines on medico-legal examination of } \\
\text { survivors of sexual violence }\end{array}$ & 88 & 54.3 \\
\hline $\begin{array}{l}\text { Identifying a medico-legal case in the Emergency } \\
\text { Department }\end{array}$ & 116 & 71.6 \\
\hline Consent for minors in the absence of parents & 113 & 76.5 \\
\hline Recognition of an acid attack & 135 & 69.7 \\
\hline Privileged communication in outbreak of infectious disease & 39 & 24 \\
\hline Medico-legal classification of injury & 135 & 83.3 \\
\hline $\begin{array}{l}\text { Manner of injury - whether accidental, self-inflicted, or due } \\
\text { to assault }\end{array}$ & 103 & 63.5 \\
\hline Duty of a nurse in a case of poisoning & 89 & 54.9 \\
\hline Observation and inference on examination of a rape survivor & 121 & 74.7 \\
\hline Sorting and prioritizing injured patients in mass casualties & 110 & 67.9 \\
\hline Medico-legal aspects of road traffic injuries & 143 & 88.2 \\
\hline Principle of confidentiality and professional secrecy & 150 & 92.6 \\
\hline Principle of patient autonomy in nursing ethics & 109 & 67.2 \\
\hline Application of bioethical principles in a clinical scenario & & \\
\hline
\end{tabular}

\#Indian Nursing Council

*Ministry of Health and Family Welfare

Most of the respondents (69.7\%) could recognize an acid attack victim while $83.3 \%$ could determine the manner of injury as self-harm based on the clinical presentation in the Emergency 
Department. However, only $24 \%$ were aware of the medico-legal classification of injury as grievous in the given case study. As regards the first and foremost duty of a nurse in a case of poisoning, $63.5 \%$ were able to correctly respond that treatment of the patient with emphasis on supportive care is the priority. Around $54.9 \%$ were able to form an inference based on the problem related to examination of a rape survivor. In relation to the medico-legal aspects of road traffic injuries, $67.9 \%$ could select the false statement that private hospitals are exempted from attending to medico-legal cases.

In a hypothetical case involving disclosure of a patient's HIV AIDS status to a relative over the phone, $88.2 \%$ of respondents answered correctly that they would maintain confidentiality in such a situation. A whopping majority (92.6\%) knew about the concept of patient autonomy in nursing ethics while $67.2 \%$ were able to apply the principles of bioethics in a clinical scenario. According to the Chi Square Test and Fisher's Exact Test, there was no association between level of awareness with selected variables such as age, gender and duration of clinical exposure (Table 3).

Table 3. Association between level of awareness and socio-demographic variables $(n=162)$

\begin{tabular}{|c|c|c|c|c|c|}
\hline \multirow[t]{2}{*}{ Socio-demographic variables } & \multicolumn{5}{|c|}{ Level of awareness } \\
\hline & Good & Fair & Poor & $\begin{array}{c}\text { Chi Square } \\
\text { Statistics }\end{array}$ & p-value \\
\hline $\begin{array}{c}\text { Age } \\
18-21 \text { years } \\
\geq 22 \text { years }\end{array}$ & $\begin{array}{l}25 \\
21 \\
\end{array}$ & $\begin{array}{l}59 \\
39 \\
\end{array}$ & $\begin{array}{c}12 \\
6 \\
\end{array}$ & 0.9049 & 0.636056 \\
\hline $\begin{array}{l}\text { Gender } \\
\text { Male } \\
\text { Female }\end{array}$ & $\begin{array}{c}2 \\
44\end{array}$ & $\begin{array}{c}6 \\
92\end{array}$ & $\begin{array}{c}3 \\
15\end{array}$ & - & $\begin{array}{l}0.217581 \\
\text { (Fisher's) }\end{array}$ \\
\hline $\begin{array}{c}\text { Duration of clinical exposure } \\
<1 \text { year } \\
1-2 \text { years } \\
3-4 \text { years }\end{array}$ & $\begin{array}{l}12 \\
11 \\
23\end{array}$ & $\begin{array}{l}25 \\
25 \\
48\end{array}$ & $\begin{array}{l}5 \\
7 \\
6\end{array}$ & 2.0893 & 0.719338 \\
\hline
\end{tabular}

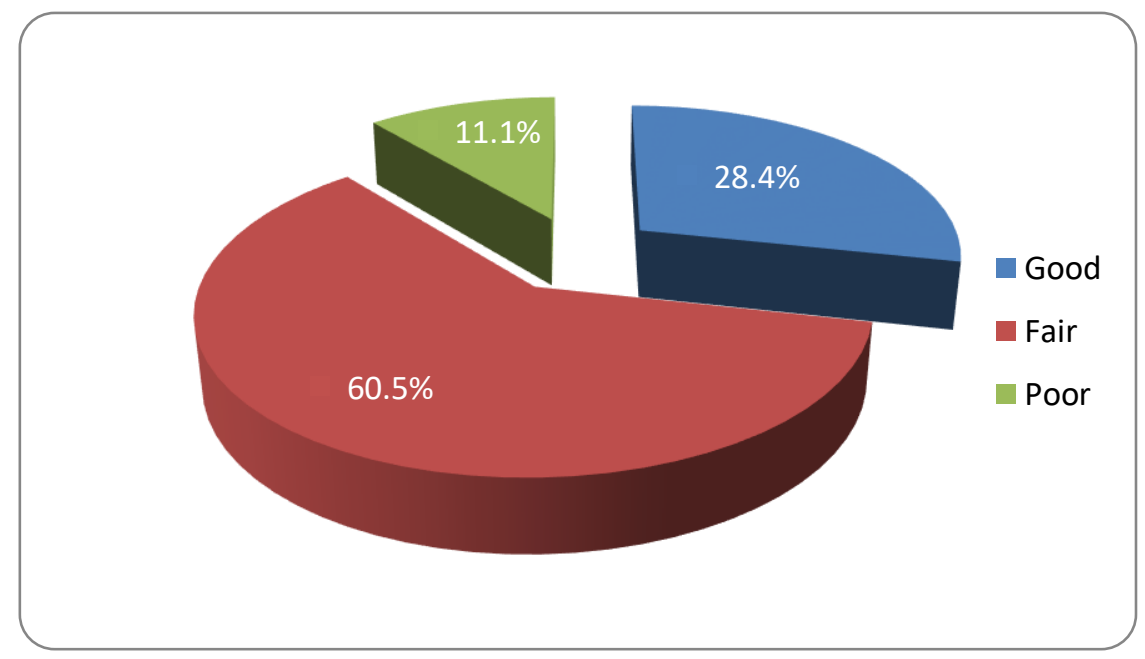

Figure 1: Level of awareness of ethical and legal issues

\section{Discussion}

The Indian Nursing Council is instrumental in evolving and administering the Code of Ethics for nurses in India [1]. Accordingly, nurses are obliged to practice within the framework of ethical, 
professional, and legal boundaries [2]. An international code of ethics for nurses was first adopted by the International Council for Nurses (ICN) in 1953 [3]. Hafez FE et al stated that nursing ethics had standards to guide the nurse to conduct herself properly, make adequate decisions and carry out actions appropriate and safe for the client and thus protect her from litigation [4].

Although the legal and ethical aspects of practice is covered extensively in the B.Sc (Nursing) curriculum, its relevance may not be understood by students due to theoretical rather than practical case based approach in teaching learning methodology. A study conducted in Malaysia in 2017 concluded that adequate knowledge of healthcare ethics is required for providing holistic care to the patient. The findings of this research comprising $82.8 \%$ of females in the sample population $(n=128)$ showed significant association between gender and knowledge of healthcare ethics among nursing students [5]. This varies from our results in that we did not find any statistically significant differences in the performance of male and female students who represented $93.2 \%$ of our sample (Table 1). Moreover, there was no relationship between level of knowledge with age and duration of clinical experience which concurs with our study (Table 3).

A study performed on 80 nursing students in Madurai revealed that $48.75 \%$ of them had inadequate knowledge on legal and ethical aspects of nursing which differs from our results [6]. Yousefzadeh $\mathrm{S}$ et al demonstrated that the majority (77.6\%) of midwifery students exhibited moderate knowledge towards observing the ethical and legal aspects of patient rights which is in agreement with the findings in the present study (Fig 1). In addition, the results of the study showed a significant relationship between total knowledge score and studying midwifery ethical codes [7]. In a study conducted on doctors in Manipur, $99 \%$ of respondents stated that it was necessary to include the Code of Ethics in the undergraduate curriculum [8].

The findings of research conducted among nurses in Bida, Nigeria revealed that professional qualification, years of experience and rank had statistical significance on some aspects of nursing ethics and law while age and sex did not [9]. Subashini SP suggested that awareness of ethical codes in nursing curriculum and providing continuing education will optimize high quality nursing care, as nursing profession faces legal issues and challenges [10]. Research carried out among 50 staff nurses of both genders in a teaching hospital in Kerala revealed that $78 \%$ of participants had inadequate knowledge regarding law and ethics in nursing [11]. The findings of a study in Nepal showed that $58.4 \%$ of nurses had inadequate knowledge on medico-legal cases in nursing and $55.4 \%$ were not aware of ethical principles in nursing [12]. On the other hand, most of our students had good awareness of the concepts of patient autonomy and confidentiality in nursing ethics. However, awareness of some medico-legal issues such as classification of injury into simple or grievous was found lacking (Table 2).

According to Iglesias MEL et al, nurses are very concerned about situations that create ethical and legal conflicts but do not feel sufficiently trained [13]. Further, research conducted in Barbados, West Indies reveal that nurses commonly encounter legal and ethical issues but are either unaware of their importance or unable to appropriately deal with these issues [14]. Knowledge of the ethical codes and legal issues related to the profession improves the quality of care, which is the ultimate end of the profession of nursing [15]. Osingada CP et al (Uganda) recommend structured Continuing Nursing Ethics Education (CNEE) programs to address basic concepts and their application in clinical practice [16].

\section{Conclusions}

In a nutshell, we can conclude that nursing students in our research have a fair awareness of the ethical and legal aspects of day-to-day practice. The importance of knowing the Code of Ethics and Professional Conduct for nurses has to be stressed right from the undergraduate level. Moreover, relevant topics like examination of a rape survivor and medico-legal classification of injury require clarification and emphasis from time to time through seminars and planned teaching activities. There is a need to reinforce learning with a more problem-based approach and introduction of clinical scenarios to help future nurses deal competently with such issues in a postpandemic world. 


\section{REFERENCES}

1. Government of India. Indian Nursing Council Act [No.48 of 1947]. New Delhi: Ministry of Health and Family Welfare; 1947.

2. Nursing Council of India. Code of Ethics and Professional Conduct, 2006 [Internet]. New Delhi: Indian Nursing Council; 2006 [cited 2020 May 05]. 5p. Available from: http://hmis.ap.nic.in/APNMC/pdfs/ethics.pdf.

3. International Council of Nurses, Svensk sjuksköterskeförening. ICN:s etiska kod för sjuksköterskor. Stockholm: Svensk sjuksköterskefören.; 2014.

4. Hafez FE, Mohamed HA, Sobeh DE. Assessment of nurses' knowledge and practice regarding professional ethics in outpatient clinics at Mansoura University Hospital. IOSR J Nurs Health Sci. 2016;5(6):20-8.

5. Annuar WSHWM, Saat NH, Razali MTA, Aung KT. Knowledge and practice of nursing students on healthcare ethics. Sch J App Med Sci 2017;5(9C):3693-9.

6. Bharathi NS, Prabha I. A Descriptive Study to Assess the Knowledge on Legal and Ethical aspects of nursing among outgoing and Final year BSc nursing students at Sacred Heart Nursing College, Madurai. Int J Nurs Educ Res 2020;8(1):105.

7. Yousefzadeh S, Zohani M, Mazlom SR, Feyzabadi MG. Knowledge and Attitude of Midwifery Students towards Observing the Ethical and Legal Standards of Patients' Rights. J Midwifery Reproductive Health. 2017;5(3):978-87.

8. Akoijam BS, Rajkumari B, Laishram J, Akoijam J. Knowledge and attitudes of doctors on medical ethics in a teaching hospital, Manipur. Ind J Med Ethics 2009;6(4):194-7.

9. Aliyu D. Knowledge, Attitude and Practice of Nursing Ethics and Law among Nurses at Federal Medical Centre, Bida. Am J Health Res 2015;3(1):32-8.

10. Subashini SP. Indian Nursing Council - Its role in evolving and administering paramedical professional ethics. Santosh Univ J Health Sci 2018;4(1):41-4.

11. Thirunavukarasu MR, Velmurugan A. Knowledge regarding law and ethics among nurses at a tertiary care hospital in rural India. Int J Community Med Public Health 2018;5(9):1-5.

12. Devi WA. Nurse's awareness on legal and ethical responsibilities in nursing. Int J Nurs Res Pract. [Internet]. 2017 [cited 2020 Jun 05];4(1):53-7.

13. Iglesias MEL, de Bengoa Vallejo RB. Nurse attitudes in relation to health care ethics and legal regulations for nursing. Acta Bioeth 2014;20(2):255-64.

14. Hariharan S, Jonnalagadda R, Walrond E, Moseley H. Knowledge, attitudes and practice of healthcare ethics and law among doctors and nurses in Barbados. BMC Med Ethics 2006;7.

15. Osingada CP, Nalwadda G, Ngabirano T, Wakida J, Sewankambo N, Nakanjako D. Nurses' knowledge in ethics and their perceptions regarding continuing ethics education: a cross-sectional survey among nurses at three referral hospitals in Uganda. BMC Res Notes 2015;8:319.

16. Moosavi S, Borhani F, Mohsenpour M. Ethical attitudes of nursing students at Shahid Beheshti University of Medical Sciences, Iran. Ind J Med Ethics 2017;2(1):14-9.

Acknowledgements: Nil

Conflict of interest: Nil

Funding: Nil 